\title{
Performance Evaluation of Engineered Structured Sorbents for Atmosphere Revitalization Systems On Board Crewed Space Vehicles and Habitats
}

\author{
David F. Howard ${ }^{1}$ \\ All Points Logistics, Huntsville, Alabama, 35812, USA \\ Jay L. Perry ${ }^{2}$ and James C. Knox ${ }^{3}$ \\ NASA Marshall Space Flight Center, Huntsville, Alabama, 35812, USA \\ and \\ Christian Junaedi ${ }^{4}$ and Subir Roychoudhury ${ }^{5}$ \\ Precision Combustion, Inc., North Haven, Connecticut, 06473, USA
}

\begin{abstract}
Engineered structured (ES) sorbents are being developed to meet the technical challenges of future crewed space exploration missions. ES sorbents offer the inherent performance and safety attributes of zeolite and other physical adsorbents but with greater structural integrity and process control to improve durability and efficiency over packed beds. ES sorbent techniques that are explored include thermally linked and pressure-swing adsorption beds for water-save dehumidification and sorbent-coated metal meshes for residual drying, trace contaminant control, and carbon dioxide control. Results from sub-scale performance evaluations of a thermally linked pressure-swing adsorbent bed and an integrated sub-scale ES sorbent system are discussed.
\end{abstract}

\section{Nomenclature}

$\begin{array}{ll}C & =\text { Celsius } \\ \mathrm{cm} & =\text { centimeter } \\ \mathrm{DC} & =\text { direct current } \\ \mathrm{F} & =\text { Fahrenheit } \\ \mathrm{kg} & =\text { kilogram } \\ \mathrm{kPa} & =\text { kiloPascal } \\ \text { micron } & =\text { micrometer } \\ \mathrm{mm} & =\text { millimeter } \\ \mathrm{Pa} & =\text { Pascal } \\ \mathrm{psi} & =\text { pound per square inch } \\ \text { slpm } & =\text { standard liters per minute } \\ V & =\text { Volt }\end{array}$

${ }^{1}$ Aerospace Engineer, AED Sustainment Engineering Division, Bldg 4484 Rm A204, Redstone Arsenal, Alabama.

${ }^{2}$ Engineer, Environmental Control Systems, NASA Marshall Space Flight Center, Space Systems Department.

${ }^{3}$ Engineer, Environmental Control Systems, NASA Marshall Space Flight Center, Space Systems Department.

${ }^{4}$ Research Engineer, 410 Sackett Point Rd., North Haven, CT 06473

${ }^{5}$ Director, Microlith ${ }^{\circledR}$ Products, 410 Sackett Point Rd., North Haven, CT 06473. 


\section{Introduction}

$\mathrm{R}$ obust atmosphere revitalization (AR) systems that are highly reliable, compact and power efficient are necessary to enable space exploration beyond the earth-moon system. These systems must provide functional flexibility by allowing easy adaptation across a variety of crewed platforms and mission objectives that require varying degrees of life support system mass recycling. Engineered substrates for catalytic and sorbent media have their origin in the chemical process and automotive industries. Work by BASF in the late 1980s and early 1990s to place catalytic coatings on static mixers raised interest by the National Aeronautics and Space Administration (NASA). Beginning in 1992, NASA-sponsored projects began to apply the Microlith ${ }^{\circledR}$ catalytic oxidation technology developed by Precision Combustion, Inc. (PCI) for automotive and gas turbine engine emissions control to crewed spacecraft trace contaminant control challenges. ${ }^{1-4}$ The Microlith ${ }^{\circledR}$ substrate is patented and trademarked by PCI. ${ }^{5}$

Following the successful catalytic oxidation technology development, attention turned to the challenge of developing more energy efficient, durable adsorbent media for combined vacuum-temperature swing regenerable processes suited for broad spectrum crewed spacecraft cabin atmosphere quality control (AQC) applications. ${ }^{6,7}$ Via a NASA-sponsored developmental project, PCI delivered a breadboard module combining carbon dioxide $\left(\mathrm{CO}_{2}\right)$ and trace contaminant control functions. ${ }^{8}$ Further development sponsored by NASA resulted in individual Microlith ${ }^{\circledR}$ modules for removing moisture, trace chemical contaminants, and $\mathrm{CO}_{2}$. These modules as well as the Microlith ${ }^{\circledR}$ based thermal catalytic reactor are process technology candidates for several core AR functional trade spaces. These include residual process air drying, trace contaminant control, and $\mathrm{CO}_{2}$ removal. $^{9}$

Process air drying upstream of the core AR trace contaminant control and $\mathrm{CO}_{2}$ removal stages provides two functions. The first function is conditioning the process air to enable efficient $\mathrm{CO}_{2}$ removal. Recovering the water for crew use is the second function. This water-saving feature is necessary for any AR subsystem design intended to enable extended duration crewed space exploration missions. Developmental work on a process air drying approach that employs the combination of packed bed and engineered structured sorbent (ESS) technologies has been conducted. The emphasis of the most recent work has been on scaling up the fixed bed, isothermal bulk desiccant (IBD) component. The IBD is the first stage of the 2 -stage process air drying equipment.

Continued developmental work on candidate process technologies for the core AR process functions has focused on the IBD component scale-up and integrated performance of Microlith ${ }^{\circledR}$-based residual dryer and $\mathrm{CO}_{2}$ removal modules. The most recent development work successfully scaled up the IBD component by a factor of $\sim 9$ to accommodate 140 standard liter/minute (slpm) flow conditions. This flow condition is consistent with that used during single Microlith ${ }^{\circledR}$ module testing accomplished by Howard et al. ${ }^{10}$ Developmental results have provided valuable information regarding temperature dynamics resulting from cyclic sorption processes, subsequent effects on performance, and how adverse performance effects can be negated by altering cycle times and relative adsorption/desorption pressures. Ultimately, process controls were defined that resulted in performance that significantly exceeded the performance goals and expanded IBD application to a greater variety of process technologies that require a dry process air feed stream. In addition to the IBD component development, the Microlith ${ }^{\circledR}$-based residual drying and $\mathrm{CO}_{2}$ removal modules designed to accommodate $140 \mathrm{slpm}$ flows were successfully tested in an integrated configuration. These modules had previously been tested alone and results were reported in Ref. 10. Results from IBD component scale-up and performance testing as well as integrated Microlith ${ }^{\circledR}$ module testing are presented and discussed.

\section{Isothermal Bulk Desiccant Development}

A water-saving bulk drying stage prior to downstream $\mathrm{AR}$ trace contaminant control and $\mathrm{CO}_{2}$ removal processes is under development by NASA. Both membrane and packed bed approaches are under consideration in the bulk drying functional trade space. Regardless of the technical approach, the primary goal is to continuously remove at least $80 \%$ and up to $100 \%$ of water from a process air stream. Ideally, the bulk dryer will operate without active heating during regeneration to minimize power requirements. This may be accomplished by using the dry AR system outlet air to regenerate the bulk dryer via a purge which returns the captured water back to the cabin atmosphere. Process optimizations such as passive thermal control and mild pressure swings are prime interests. Development of a bulk drying stage for a water-save AR process at the NASA's Marshall Space Flight Center (MSFC) has focused on a silica gel-based IBD system with emphasis on evaluating the performance benefits of thermally linking the adsorbing and desorbing beds using a specially designed test article that trades thermal optimization for simplicity. General operational details and performance results of each approach are presented by the following summary. Two primary aspects of the IBD component evaluated during the testing include effects of particle size and mild pressure swings to improve performance. 


\section{A. Standard Operation}

Under standard operation, the bulk desiccant takes in process air directly from the habitable cabin and passes it through a silica gel sorbent bed to remove humidity. The dehumidified air is then available for downstream processing. Concurrently, the alternate silica gel bed is purged with dry gas from the $\mathrm{CO}_{2}$ removal system outlet for regeneration. The process continues for a half cycle after which diverter valves at the inlet and outlet of the bulk desiccant redirect the process and purge gas flows such that the adsorbing and desorbing beds are switched. This process continues indefinitely to provide a constant dehumidified gas stream. For test purposes, the inlet air humidity level is controlled using a humidifying membrane, and the dry purge gas is facility-supplied missile grade air (MGA). A schematic of the test setup is provided in Fig. 1. A metering valve located at the process air outlet enabled a mild pressure swing component between the adsorbing and desorbing sorbent beds.

\section{B. Design for Thermal Optimization}

Process optimization by minimizing sorption temperature swings was evaluated under low flow rate conditions using a 4-column test article shown by Fig. 2, where two beds were divided into two rectangular columns such that adjacent columns were of the alternate bed. This configuration assures that an adsorbing column is always adjacent to a desorbing column. In addition, each of the columns contained an aluminum (Al) foam lattice brazed to the column walls. All columns were filled with silica gel beads ranging from $0.5 \mathrm{~mm}-$ $0.7 \mathrm{~mm}$ in diameter. Each end of the columns was capped by a thin perforated plate covered by a 50-micron wire screen for sorbent retention. The process and purge gas flows are split into the multicolumn flow paths using a manifold fabricated using a stereo lithography rapid prototyping technique. The intent of this configuration was to efficiently exchange heat generated from adsorption
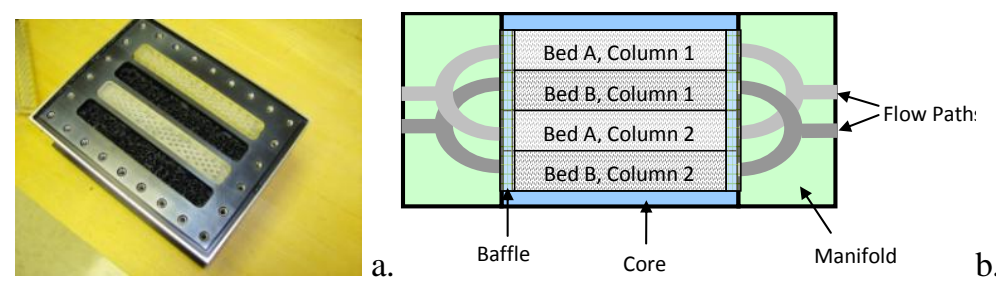

Figure 2. Subscale IBD test article. a) view showing four chambers b) schematic showing chamber manifold configuration.

to the desorbing bed, yielding near isothermal sorption processes. The use of $\mathrm{Al}$ foam to transport heat from adsorbing to desorbing processes is a technique pioneered by Hamilton Sundstrand in their development of amine-based $\mathrm{CO}_{2}$ removal systems ${ }^{12}$ and has been developed for vacuum swing adsorption of water with silica gel in support of the Sorbent-Based Atmosphere Revitalization (SBAR) project ${ }^{13}$.

The IBD performance testing consisted of an inlet dew point of $10{ }^{\circ} \mathrm{C}\left(50^{\circ} \mathrm{F}\right)$ and a flow rate range of $10-17$ slpm with half cycles ranging from 7-20 minutes. The subscale 4-column IBD test article steady state performance results are shown by Fig. 3. The temperature change between inlet and outlet was less than $2{ }^{\circ} \mathrm{C}$ for each test case.

\section{Scaling and Design Simplification}

To minimize system complexity and simplify fabrication of the scaled-up IBD unit, the multi-column bed with an $\mathrm{Al}$ foam matrix was reduced to a 2-column, 2-bed design using $\mathrm{Al}$ honeycomb as the metal thermal carrier. This approach, while not as thermally optimized, simplified the manifold design and enabled using larger sized silica gel 
particles to reduce pressure drop. To maintain thermal optimization similar to the subscale IBD test article, additional columns would be needed to accommodate scale-up that contributes to fabrication complexity. However, design analysis calculations, assuming the Al honeycomb would maintain a relatively uniform temperature, suggested adequate thermal dampening of the sorption processes. Figure 4 shows the packed test article with one manifold removed and the article installed into the test rig.

Initial breakthrough and performance testing revealed adsorption temperature increases greater than

expected. The unit was disassembled and inspected and the following observations were made. The packing process caused some of the $\mathrm{Al}$ honeycomb material to separate from the housing walls, eliminating thermal contact. The contact circuit between the Al honeycomb and the housing wall relied on pressure from the slightly oversized $\mathrm{Al}$ honeycomb sections. Further evaluation of the $\mathrm{Al}$ honeycomb material revealed the construction consisted of thin stacked sections that appeared to be glued together, resulting in a lower thermal conductivity than a singular Al substance. To determine the extent of performance gained by the $\mathrm{Al}$ honeycomb inserts, they were removed and preliminary tests repeated. Results showed only modest performance and thermal improvements with the Al honeycomb, differences that lie within experimental errors. All subsequent testing and performance data provided is without the $\mathrm{Al}$ honeycomb inserts.

The superficial velocity through the sub-scale packed sorbent bed at $17 \mathrm{slpm}$ was used as the scaling parameter. This parameter incorporates process air flow rate, bed cross-sectional area, and the sorbent void fraction. However, since the bed width and the distance between the walls for the scaled up test article were minimized to promote heat transfer with the sorption processes, the superficial velocity increased relative to that observed at the $17 \mathrm{slpm}$ condition. Cyclic performance data, shown by Figs. 5 and 6, were acquired for the scaled up IBD test article at 140 slpm process flow rate with an inlet water partial pressure of $1.2 \mathrm{kPa}$. The purge was set at $95 \%$ of the process flow, 136 slpm. Test runs were conducted using half cycle times ranging from 1-5 minutes and pressure swings of $0 \mathrm{kPa}, 6.9$ $\mathrm{kPa}(1 \mathrm{psi})$, and $13.8 \mathrm{kPa}(2 \mathrm{psi})$ during which the adsorbing bed pressure is elevated relative to desorbing bed pressure. Pressure swings were obtained by adding a metering valve at the system outlet.

The data shown in Figs. 5 and 6 indicate significant drying performance gains are realized with both shortening of the half cycle time and instituting mild pressure swings. In comparison to the low flow thermally optimized test article, the long half cycle performance was significantly compromised, however removal efficiency was recovered by operating at shorter half cycles. Figure 7 shows the temperature rise between the inlet and outlet process air. This

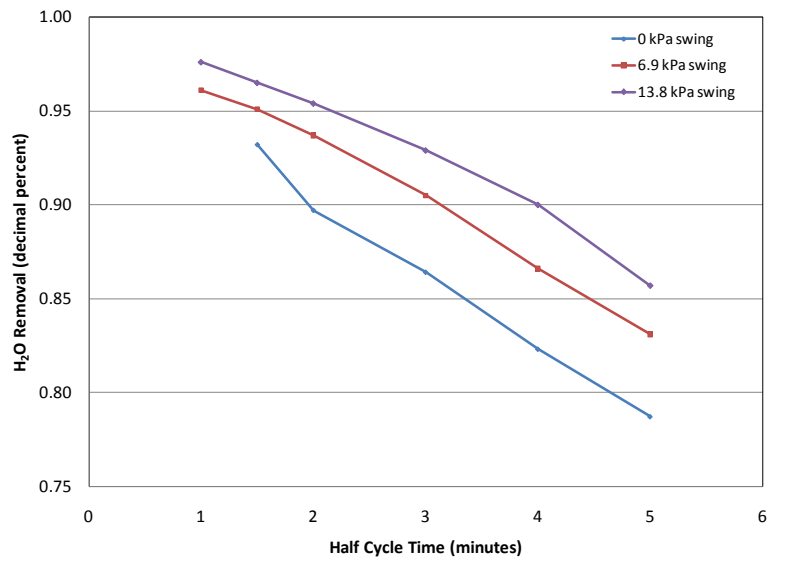

Figure 5. Steady state performance at 140 slpm.

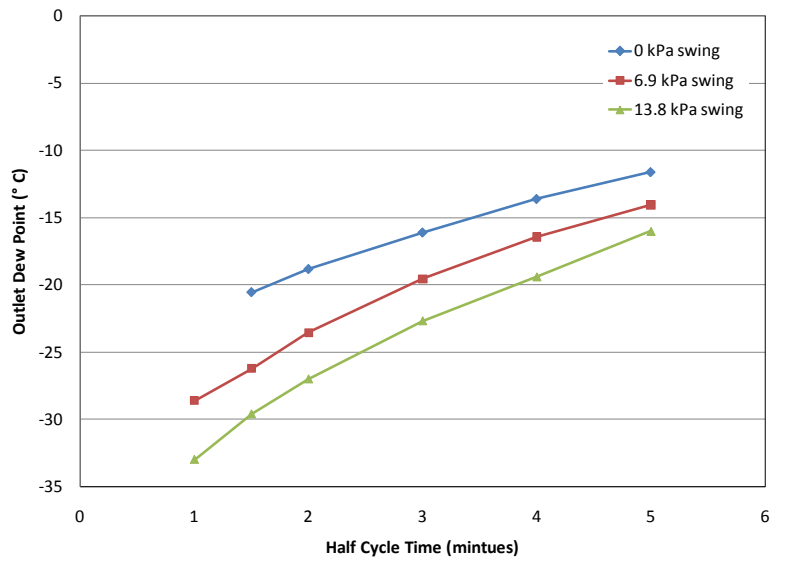

Figure 6. Average outlet dew point at 140 slpm.

4

American Institute of Aeronautics and Astronautics 
figure indicates that a shorter half cycle time can be used to reduce the negative performance impacts of large temperature swings.

As indicated in Fig. 7, the temperature rise at cycle times under two minutes is minimal, and compares to the temperature rise of the thermally optimized low flow test article. If operational factors enable cycle times of such duration, thermal optimization would likely result in only modest performance gains and would not offset the increased hardware complexity; however this must be traded against the system impacts of short cycle times.

\section{Effect of Particle Size}

The IBD was tested using a reduced particle size silica gel to evaluate the effect of increased sorbent surface area on the bed performance. Standard size (1,410-3,360 micron) Grace Davidson grade 40 silica gel granules were reduced by fracturing and sieving to obtain a particle size range of $850-1,400$ microns. The reduced size sorbent was then loaded into the $140 \mathrm{slpm}$ IBD test article for testing. Additionally a larger diameter silica gel, Sorbead$\mathrm{R}$, was tested and compared to the nominally sized grade 40. Both of the alternate materials were operated with half cycles ranging from one to five minutes. For each cycle time the adsorbing bed pressure was increased $0 \mathrm{kPa}$ and $6.9 \mathrm{kPa}$ above the desorbing bed. All of the test cases were run with an inlet process air dew point of $10{ }^{\circ} \mathrm{C}$. The results, shown in Fig. 8, demonstrate that the smaller particle size performance was significantly greater than the unprocessed grade 40 . The Sorbead-R had the lowest performance for this application. Because the Sorbead-R material is both a larger particle bead and a different formulation than the standard grade 40 silica gel, it is inconclusive which of the characteristics are responsible for the lower performance. Both characteristics may contribute to this result.

Inducing a $6.9-\mathrm{kPa}$ pressure swing by increasing the adsorption pressure yielded the results shown in Fig. 9. The combination of a reduced particle size coupled with the pressure swing resulted in removal efficiency of $>98 \%$ while operating on a one minute half cycle. A comparison of removal efficiencies for the three silica gel variations for half cycles ranging from one to five minutes is presented in Fig. 9.

The data indicates a clear trend of improved removal efficiency as a function of reduced half cycle duration and sorbent particle size. This trend indicates that further improvements to the removal efficiency are attainable if the half cycle could be further reduced (i.e., below one minute). This is significant because the IBD performance is approaching the total desiccation required for the $\mathrm{CO}_{2}$ removal stage at the tested flow rates. If total desiccation can be achieved, the requirement for a downstream residual drying component could be eliminated, significantly reducing the number of components and subsequent weight, volume, and power of an ESS based $\mathrm{CO}_{2}$ removal system. Fig. 10 identifies the IBD performance operating with $850-1,400$ micron silica gel on a $6.9 \mathrm{kPa}$ pressure swing versus the bulk desiccant and total desiccant re-

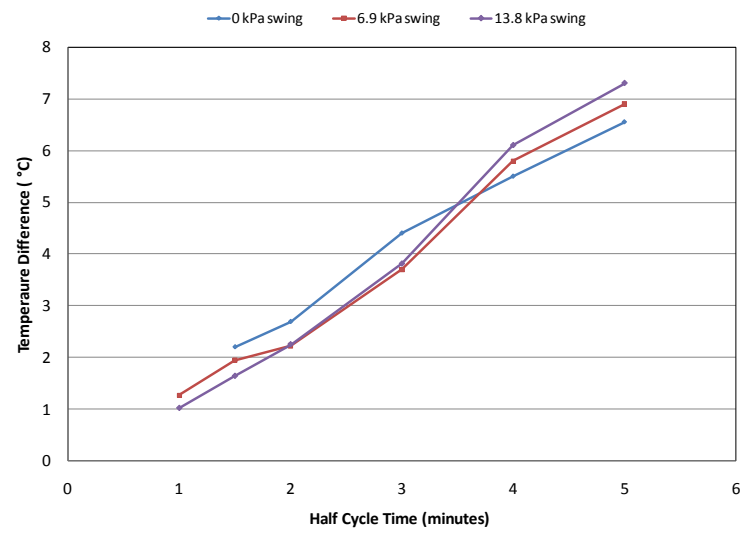

Figure 7. Cycle time effects on peak temperature rise at $140 \mathrm{slpm}$.

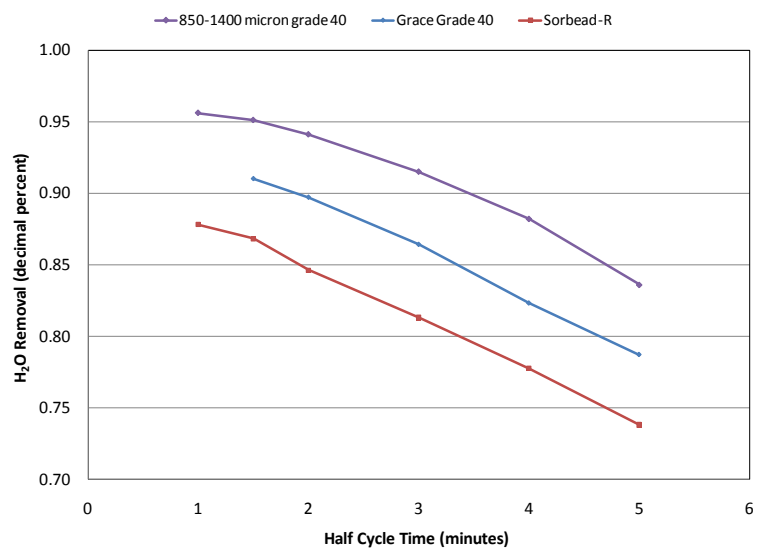

Figure 8. IBD water removal efficiency. Influence of silica gel type and half cycle time without pressure swing.

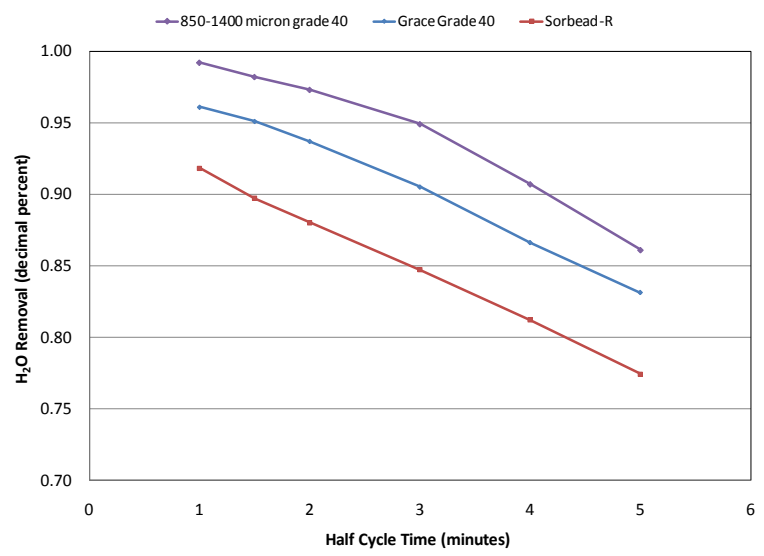

Figure 9. IBD water removal efficiency. Influence of silica gel type and half cycle time when employing $6.9 \mathrm{kPa}$ pressure swing. 
quirements for integration with zeolite based $\mathrm{CO}_{2}$ removal system. As illustrated in Fig. 10, a removal performance with an average outlet $\mathrm{H}_{2} \mathrm{O}$ partial pressure of $126.6 \mathrm{~Pa}\left(-17.8{ }^{\circ} \mathrm{C}\right.$ dew point) is required for compatibility with an AR system containing a residual drying element. The data show this performance level was exceeded while operating on a 4-minute half cycle. The performance requirement for total desiccation is an average outlet $\mathrm{H}_{2} \mathrm{O}$ partial pressure of $1.3 \mathrm{~Pa}\left(-56.7^{\circ} \mathrm{C}\right.$ dew point $)$. The best performance achieved was an average outlet $\mathrm{H}_{2} \mathrm{O}$ partial pressure of $2.4 \mathrm{~Pa}\left(-41.1^{\circ} \mathrm{C}\right.$ dew point).

From the performance trend, it appears that total desiccation may be reached with approximately 30 -second half cycle duration. However, it was determined that the current test configuration with ball-style diverter valves, having an actuation time of approximately four seconds, would not be adequate for testing at cycle times below one minute. Shorter cycle times result in the valve transition time taking up too much of the cycle time, reducing overall removal efficiency. Figure 11 shows an alternative approach that uses fast-actuation 2-way servo valves. Such an approach is feasible and could be used with the existing IBD test article for a reasonable investment. Such valves actuate in the range of 30 milliseconds and can have a lifetime of up to 2,000,000 duty cycles.

\section{E. Pressure Drop Considerations}

The combination of increasing pressure during the adsorption half cycle and reducing the particle size incurs a much larger system pressure drop than the original configuration with nominal size silica gel and equivalent adsorption/desorption bed pressures. The total system pressure drop increased from a modest $0.75 \mathrm{kPa}$ to 9.96 $\mathrm{kPa}$ which included $2.99 \mathrm{kPa}$ through beds plus $6.97 \mathrm{kPa}$ for the pressure swing. Market research was performed to identify commercial fans providing high efficiency in the desired flow rate and pressure drop range. It was found that few fans or blowers meet the required pressure drop, and that these generally have a much higher flow range, resulting in oversized motors for this application. This is probably due to market demand rather than inherent design limitations. However, one commercially available fan from Ametek is capable of meeting the pressure drop requirements for flows up to 424.8 slpm with 150 Watts of

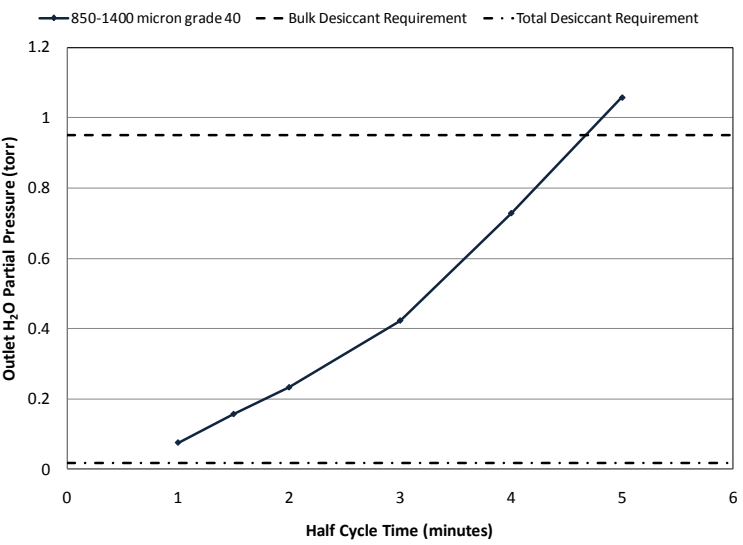

Figure 10. IBD performance vs. bulk and total desiccation criteria at $6.9 \mathrm{kPa}$ pressure swing.

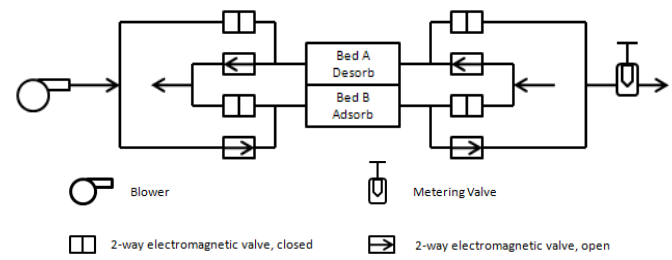

Figure 11. Potential configuration for total dryer operations.

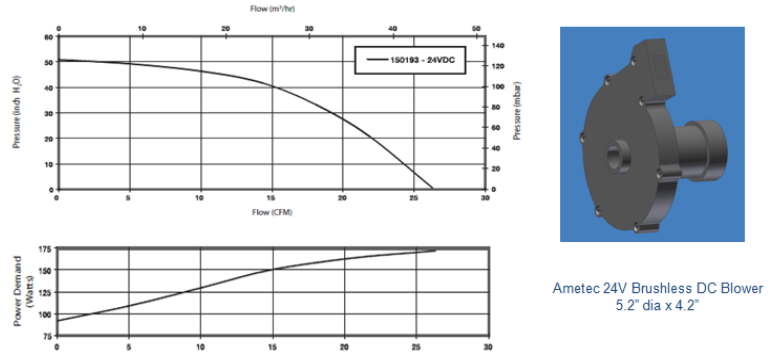

Figure 12. Blower for potential application with 6.9 kPa pressure swing. ${ }^{13}$

power. Details of the Ametek 24V DC blower are provided by Fig. $12 .{ }^{13}$ This blower is believed to be an excellent candidate for testing and evaluation.

\section{F. Isothermal Bulk Desiccant Observation Summary}

Key observations obtained from testing the IBD at 140 slpm are the following:

- The minimum dew point of $-17.8^{\circ} \mathrm{C}\left(126.6 \mathrm{~Pa} \mathrm{H}_{2} \mathrm{O}\right)$ for integration with a Microlith ${ }^{\circledR}$ based residual dryer was achieved using standard size (6-12 US Standard Sieve mesh) grade 40 silica gel, a 2-minute half cycle, and $747 \mathrm{~Pa}$ total pressure drop.

- After reducing the particle size of the Grade 40 silica gel to 14-18 US Standard Sieve mesh, it met the performance goal using a 4-minute half cycle and $2.99 \mathrm{kPa}$ total pressure. Valve duty cycle decreased by $50 \%$ while pressure drop increased by $2.24 \mathrm{kPa}$.

- The highest water removal was achieved by reducing the cycle time to one minute and adding a $6.9 \mathrm{kPa}$ pressure swing. This resulted in an outlet dew point of $-41.1^{\circ} \mathrm{C}$ dew point $\left(10.7 \mathrm{~Pa} \mathrm{H}_{2} \mathrm{O}\right)$. This operation increases the total pressure drop to $\sim 9.96 \mathrm{kPa}$. 
- Residual drying modules may be eliminated if water removal down to $-56.7^{\circ} \mathrm{C}$ dew point $\left(1.3 \mathrm{~Pa} \mathrm{H}_{2} \mathrm{O}\right)$ could be achieved by the bulk desiccant. Current trends indicate this may be possible with half cycles under 1 minute but much more rapid valve transition time of $\sim 4$ seconds will be required.

- The primary air mover would be required to provide the needed system flow at $>9.96 \mathrm{kPa}$.

\section{Microlith ${ }^{\circledR}$ Adsorber Development}

Precision Combustion, Inc. (PCI), via NASA-sponsored projects, has been developing regenerable Microlith ${ }^{\circledR}$ based adsorber modules for the separation of air constituents such as humidity, $\mathrm{CO}_{2}$, and trace contaminants to function in either closed or open loop operations. The Microlith ${ }^{\circledR}$ adsorbers use a patented technology developed by PCI to coat expanded metal with zeolite sorbent crystals to produce a structured sorbent. An advantage of this configuration is that can be thermally regenerated by passing a current through the electrically-resistive expanded metal. Previous developmental work has focused on testing individual Microlith ${ }^{\circledR}$-based adsorber modules for residual humidity removal, trace contaminant removal, and $\mathrm{CO}_{2}$ removal. The most recent developmental work evaluated the integrated operation of the residual humidity removal and $\mathrm{CO}_{2}$ removal adsorber modules.

\section{A. Combined Module Testing}

Testing was performed on the Microlith ${ }^{\circledR}$-based residual humidity removal and $\mathrm{CO}_{2}$ adsorbers to validate functionality in an integrated system. The test configuration consisted of two 140-slpm modules, one each to remove residual moisture and $\mathrm{CO}_{2}$. The modules operated continuously, alternating between adsorption and desorption half cycles. A simplified schematic of the test operation is provided in Fig. 13.

Nominal adsorption operation consisted of providing a controlled airstream consisting of $667 \mathrm{~Pa} \mathrm{CO}_{2}$ at a dew point of $-17.8{ }^{\circ} \mathrm{C}$ at the inlet. The inlet dew point is controlled to represent the outlet of a bulk desiccant process (i.e. the IBD described earlier). Other bulk desiccant technologies such as membranes could be used as well for pre-conditioning the airstream prior to the residual dryer. The $\mathrm{CO}_{2}$ partial pressure in the process air was maintained at $667 \mathrm{~Pa}$ to represent the threshold for continuous human exposure ${ }^{14}$. A series of tests were run at various cycle times and regeneration temperatures to determine the operating parameters that (1) resulted in a continuous removal rate of $1 \mathrm{~kg} \mathrm{CO}_{2} /$ day and (2) optimized efficiency with regards to power consumption. This removal rate is roughly equivalent to the average metabolic production of $\mathrm{CO}_{2}$ by a single person. The most efficient performance was achieved while operating on a 20 -minute half cycle, with a peak desiccant module desorption temperature of $104.4{ }^{\circ} \mathrm{C}$ and a peak $\mathrm{CO}_{2}$ adsorber temperature of $93.3{ }^{\circ} \mathrm{C}$. Average power and daily removal rates are calculated as if there is a

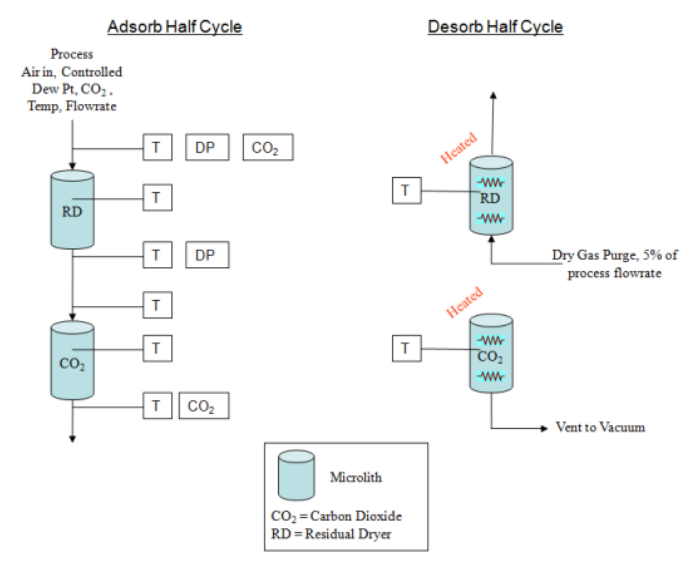

Figure 13. Integrated Microlith ${ }^{\circledR}$-based residual drying and $\mathrm{CO}_{2}$ removal adsorber modules showing adsorb and desorb configurations.

second set of modules to perform continuous adsorption-desorption cycles. These results were compared to test data from individual modules as reported in Ref. 10, and effects due to integrated module operations were identified.

\section{B. Steady State Combined Module Performance}

\section{1. $\mathrm{CO}_{2}$ Adsorption Performance}

The steady state cyclic $\mathrm{CO}_{2}$ removal performance with the optimized operational parameters (140 slpm, $667 \mathrm{~Pa}$ $\mathrm{CO}_{2},-17.8{ }^{\circ} \mathrm{C}$ dew point, 20-minute half cycle) is provided in Fig. 14. Results in Fig. 14 indicate that the module reduced the average $\mathrm{CO}_{2}$ partial pressure from the process air stream from $667 \mathrm{~Pa}$ to $400 \mathrm{~Pa}$, which met the requirement to remove $1 \mathrm{~kg} \mathrm{CO}_{2} /$ day from the process air.

A typical outlet $\mathrm{CO}_{2}$ concentration profile of the adsorption half cycle for this test case can be seen in Fig. 15 . The outlet $\mathrm{CO}_{2}$ concentration is transient throughout the half cycle. The profile shows an early peak due to the sorbent temperature, which is high initially due to thermally desorption in the previous half cycle. Residual $\mathrm{CO}_{2}$ loading in the sorbent also contributes to immediate breakthrough. The start time in the plot is not the actual test start time, rather, it is the start of an arbitrary half-cycle after cyclic steady state conditions have been acheived. 


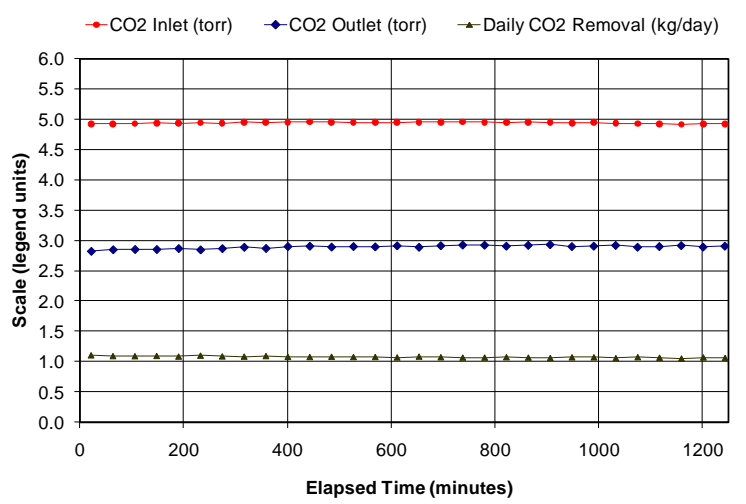

Figure 14. $\mathrm{CO}_{2}$ removal during integrated adsorber module testing using a 20-minute half cycle.

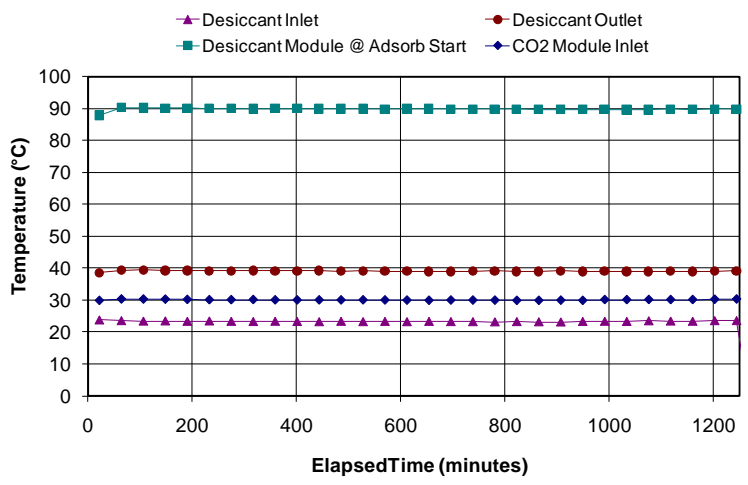

Figure 16. Adsorption module temperatures using a $7 \mathrm{lpm}$ regeneration purge.

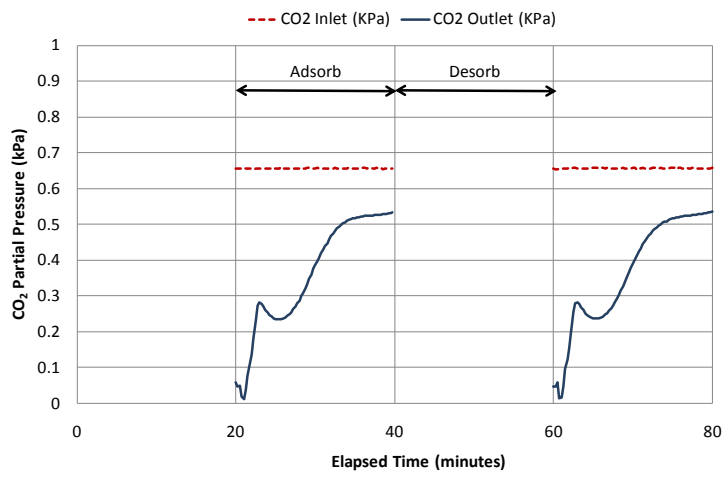

Figure 15. Inlet and outlet partial pressure profiles from the $\mathrm{CO}_{2}$ adsorber module.

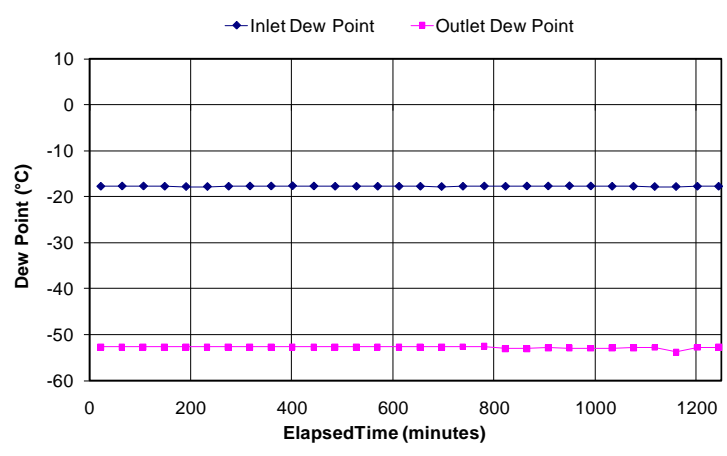

Figure 17. Average cyclic residual dryer water
removal using a 20 -minute half cycle.

The average process air inlet temperature into the $\mathrm{CO}_{2}$ removal adsorber is higher than the system inlet air temperature as a result of residual heat carryover from the desorption cycle. This effect is demonstrated in Fig. 16. At the beginning of the adsorption cycle, the internal components of the desiccant module are above $87.8^{\circ} \mathrm{C}$. The process air entering the residual drying bed at $23.9{ }^{\circ} \mathrm{C}$ quickly cooled down the residual dryer but the effect subsequently increased the temperature into the $\mathrm{CO}_{2}$ removal sorbent bed to $29.4{ }^{\circ} \mathrm{C}$. The increase in temperature from $23.9^{\circ} \mathrm{C}$ to $29.4{ }^{\circ} \mathrm{C}$ reduced the $\mathrm{CO}_{2}$ removal rate by approximately $10 \%$ compared to the individual module testing, where the inlet air to the $\mathrm{CO}_{2}$ module was provided at $23.9^{\circ} \mathrm{C}$. However, this marginal loss in performance is believed to outweigh the added complexity and power requirements of incorporating a heat exchanger to reduce the process air temperature entering the $\mathrm{CO}_{2}$ removal module.

\section{Residual Drying Adsorption Performance}

The average steady state cyclic performance of the residual drying Microlith ${ }^{\circledR}$ adsorber is presented in Fig. 17. The inlet dew point was held constant at $-17.8^{\circ} \mathrm{C}$ simulating the output from the IBD assembly. The module continually reduced the moisture content of the air stream to below $-51.1{ }^{\circ} \mathrm{C}$. Typically, a dew point of $-56.7^{\circ} \mathrm{C}$ or lower is targeted prior to flowing into a zeolite-based $\mathrm{CO}_{2}$ removal bed, but this humidity level proved adequate to obtain the performance observed in Fig. 17. It is suspected that the actual dew point was lower than the measured $-52.2{ }^{\circ} \mathrm{C}$, but residual moisture in the sample lines potentially produced higher than actual dew point readings. This is a condition that is often noted when running a dry purge gas through sample lines that previously contained humid air.

3. Desorption Operation and Performance

During desorption of the Microlith ${ }^{\circledR}$-based adsorbers, a DC power supply applies current to the expanded metal substrate generating heat resistively. Power is applied until the prescribed desorption temperature is reached. Concurrently, a purge gas flows through the desiccant adsorber and a vacuum is applied to the $\mathrm{CO}_{2}$ adsorber. The purge gas in the desiccant adsorber simulates a water recovery function where the humidity is returned to the cabin and the vacuum applied to the $\mathrm{CO}_{2}$ module simulates either dumping the $\mathrm{CO}_{2}$ to space vacuum or pumping $\mathrm{CO}_{2}$ to a reduction process for reclamation of oxygen. Figure 18 shows a thermal profile of the adsorbers as they progress through repeated adsorbing and desorbing half cycles. The desorbing desiccant bed was heated to $107.2{ }^{\circ} \mathrm{C}$ while simulta- 
neously purging with dry gas at $7 \mathrm{slpm}$. The duration of heating for the residual dryer to meet the prescribed temperature was approximately seven minutes. For the remainder of the half cycle purge gas continued to carry away the water while the module cooled to approximately $87.8^{\circ} \mathrm{C}$. Concurrent to the residual dryer desorption, the $\mathrm{CO}_{2}$ removal module is heated and evacuated with a small vacuum pump. As shown in Fig. 18, the $\mathrm{CO}_{2}$ module desorption temperature was set at $65.6^{\circ} \mathrm{C}$ and required approximately five minutes to reach temperature. The module pressure is maintained at less than 133.3 Pa for the remainder of the half cycle desorption phase. It should be noted that the actual temperature inside the $\mathrm{CO}_{2}$

removal module is higher than measured when under vacuum because of the proximity of the thermocouple to the sorbent and the absence of air inside the module to transport the heat from the sorbent to the thermocouple. This is demonstrated by an increase in the measured temperature of the module at the start of the subsequent adsorption cycle. This is also shown in Fig. 18 as the temperature measurement increases from $65.6{ }^{\circ} \mathrm{C}$ to $>76.7^{\circ} \mathrm{C}$ prior to cooling down.

Cyclic desorption module temperatures and associated power data are provided in Fig. 19. From Fig. 19, the peak heater temperatures for both the desiccant and $\mathrm{CO}_{2}$ removal during the half cycle desorption phase, the average heater power used to heat each adsorber, and the total desorption heater power are identified. The peak residual dryer temperature of $104.4{ }^{\circ} \mathrm{C}$ was consistently obtained while the peak $\mathrm{CO}_{2}$ removal module temperature of $76.7^{\circ} \mathrm{C}$ was repeatedly reached. This correlates to an average cyclic power usage of $38 \mathrm{Watts}$ for the $\mathrm{CO}_{2}$ removal module and 45 Watts for the residual dryer for a combined average heater power of 83 Watts.

Table 1 summarizes key performance parameters for three sub-scale integration options compared to the International Space Station (ISS) Carbon Dioxide Removal Assembly (CDRA) process scaled to 140 slpm flow conditions. Two integration options are considered. The first is the IBD coupled with residual dryer and $\mathrm{CO}_{2}$ removal modules. Two silica gel particle sizes are considered for this option. The second option is a total desiccant IBD coupled with $\mathrm{CO}_{2}$ removal modules. Predicted integrated performance observations for these options are the following:

- Predicted power savings are a modest $8 \%$ compared to the CDRA for the IBD with $\mathrm{H}_{2} \mathrm{O}$ and $\mathrm{CO}_{2} \mathrm{Microlith}^{\circledR}$ modules.

- Predicted mass and volume for the IBD with $\mathrm{H}_{2} \mathrm{O}$ and $\mathrm{CO}_{2}$ Microlith ${ }^{\circledR}$ is $174 \%$ and $269 \%$, respectively, of the CDRA.

- The isothermal total desiccation with only the $\mathrm{CO}_{2}$ Microlith ${ }^{\circledR}$ compares the most favorably to the CDRA with mass, power, and volume at $100 \%, 68 \%$, and $144 \%$ of the CDRA. Sub-scale performance, however, must be extrapolated to 30 -second cycles.

- The IBD with 14-18 mesh silica gel and $\mathrm{H}_{2} \mathrm{O}$ and $\mathrm{CO}_{2}$ Microlith ${ }^{\circledR}$ and added pressure swing does not appear to provide any advantage due to high blower power.

American Institute of Aeronautics and Astronautics 
Table 1. Integrated ESS process options compared to the ISS CDRA scaled to $140 \mathrm{slpm}$.

\begin{tabular}{|c|c|c|c|c|}
\hline \multirow[b]{2}{*}{$\begin{array}{l}\text { PERFORMANCE } \\
\text { PARAMETERS }\end{array}$} & \multicolumn{4}{|c|}{ OPTION } \\
\hline & ISS CDRA & $\begin{array}{c}\text { 6-14 mesh IBD } \\
\text { with Residual } \\
\text { Dryer and } \mathrm{CO}_{2} \\
\text { Module }\end{array}$ & $\begin{array}{c}14-18 \text { mesh IBD } \\
\text { with Residual } \\
\text { Dryer and } \mathrm{CO}_{2} \\
\text { Module }\end{array}$ & $\begin{array}{c}\text { 14-18 mesh } \\
\text { Total Desiccant } \\
\text { with } \mathrm{CO}_{2} \\
\text { Module }\end{array}$ \\
\hline \multicolumn{5}{|c|}{ Process Conditions } \\
\hline Flow Rate (lpm) & 140 & 140 & 140 & 140 \\
\hline IBD Outlet Dew Point $\left({ }^{\circ} \mathrm{C}\right)$ & N/A & -17.8 & -17.8 & N/A \\
\hline IBD Half Cycle (minutes) & N/A & 2 & 4 & N/A \\
\hline Total Dessicant Outlet Dew Point $\left({ }^{\circ} \mathrm{C}\right)$ & N/A & N/A & N/A & -57.7 \\
\hline Total Dessicant Half Cycle (seconds) & N/A & N/A & N/A & 30 \\
\hline Desiccant Outlet Dew Point $\left({ }^{\circ} \mathrm{C}\right)$ & -65 & N/A & N/A & N/A \\
\hline \multicolumn{5}{|c|}{ Pressure Drop Estimate } \\
\hline IBD Pressure Drop $(\mathrm{kPa})$ & 0 & 0.747 & 2.24 & 2.24 \\
\hline IBD Pressure Swing $(\mathrm{kPa})$ & 0 & 0 & 0 & 6.9 \\
\hline Desiccant Pressure Drop (kPa) & 1.1 & 0.25 & 0.25 & 0 \\
\hline $\mathrm{CO}_{2}$ Module Pressure Drop $(\mathrm{kPa})$ & 0.7 & 0.25 & 0.25 & 0.25 \\
\hline Total $(\mathrm{kPa})$ & 1.8 & 1.247 & 2.74 & 9.39 \\
\hline \multicolumn{5}{|c|}{ Power Estimate } \\
\hline Blower Power @ 44\% efficiency (W) & 9.3 & 6.6 & 14.5 & 49.8 \\
\hline Desiccant heater Power (W) & 0 & 92 & 92 & 0 \\
\hline Sorbent Heater Power $(\mathrm{W})$ & 176.5 & 72 & 72 & 72 \\
\hline Total $(\mathrm{W})$ & 186 & 171 & 179 & 122 \\
\hline \multicolumn{5}{|c|}{ Mass Estimate } \\
\hline IBD Mass (kg) & 0 & 5.4 & 5.4 & 0 \\
\hline ITD Mass (kg) & 0 & 0 & 0 & 5.4 \\
\hline Desiccant Mass (kg) & 4.9 & 8.6 & 8.6 & 0 \\
\hline $\mathrm{CO}_{2}$ Module Mass $(\mathrm{kg})$ & 6.5 & 8.6 & 8.6 & 8.6 \\
\hline Total (kg) & 23 & 40 & 40 & 23 \\
\hline \multicolumn{5}{|c|}{ Volume Estimate } \\
\hline IBD Volume (liters) & 0 & 1.75 & 1.75 & 0 \\
\hline ITD Volume (liters) & 0 & 0 & 0 & 1.75 \\
\hline Desiccant Volume (liters) & 3.4 & 10.4 & 10.4 & \\
\hline $\mathrm{CO}_{2}$ Module Volume (liters) & 4.8 & 10.4 & 10.4 & 10.4 \\
\hline Total (liters) & 16 & 43 & 43 & 23 \\
\hline
\end{tabular}

\section{Full Scale Regenerable Microlith ${ }^{\circledR}$-based Adsorber Development}

An effort to design, fabricate, and assemble adsorbers capable of accommodating $>560$ slpm was conducted in conjunction with integrated testing of the 140 slpm scale Microlith ${ }^{\circledR}$ adsorbers described in the previous section. Advancements in Microlith ${ }^{\circledR}$ sorbent loading are shown in Table 2. For this effort two residual dryers and two $\mathrm{CO}_{2}$ removal adsorbers were built with performance targeting an overall system capability equivalent to a 4-person metabolic load.

Performance from the 140-slpm scale Microlith ${ }^{\circledR}$ adsorbers was used to size the modules, with the additional constraint that they operate on a 30-minute (or greater) half cycle duration. Since PCI was able to obtain a significantly higher sorbent density compared to the $140 \mathrm{slpm}$ modules, the new modules are expected to be able to operate on an even longer half cycle and reduce overall power consumption.

Table 2. Microlith ${ }^{\circledR}$ sorbent loading advancements.

\begin{tabular}{|l|c|c|c|}
\hline SUBSTRATE & ADSORBENT & $\begin{array}{c}\text { SORBENT } \\
\text { LOADING } \\
\left(\mathbf{m g} / \mathbf{c m}^{\mathbf{2}}\right)\end{array}$ & $\begin{array}{c}\text { SORBENT } \\
\text { LOADING } \\
\text { INCREASE } \\
(\boldsymbol{\%})\end{array}$ \\
\hline $\begin{array}{l}\text { Insulating } \\
\text { fiber mesh }\end{array}$ & Zeolite 13X & 10.54 & $\sim 13$ \\
\cline { 2 - 4 } $\begin{array}{l}\text { Microlith } \\
\text { substrate }\end{array}$ & Zeolite 5A & 9.30 & $\sim 20$ \\
\cline { 2 - 4 } & Zeolite 13X & 5.12 & $\sim 10$ \\
\hline
\end{tabular}




\section{Summary}

Two candidate process technologies suitable for application to a flexible core atmosphere revitalization subsystem process architecture were tested and the results evaluated. The heaterless, low power IBD was scaled up from 17 to 140 slpm process flow rate, and demonstrated functionality at a range of performance levels required for integration with the Microlith ${ }^{\circledR}$-based residual drying adsorber. Performance was demonstrated within $1.3 \mathrm{~Pa}$ of the partial pressure of water required to obtain a total drying capability of achieving the total dryer performance goal which could potentially eliminate the need for a residual drying element.

The 140-slpm regenerable Microlith ${ }^{\circledR}$-based adsorbers demonstrated integrated humidity and $\mathrm{CO}_{2}$ removal capability equivalent to a single person metabolic load of $1 \mathrm{~kg} \mathrm{CO}_{2} /$ day. Process parameters throughout the alternating adsorbing and desorbing half cycles were evaluated to understand temperature transients and their effect on performance. Power measurements were made and scaling parameters applied to predict performance of a full scale system.

Additionally, adsorber modules capable of handling the metabolic load for four people were designed and built based on the results obtained from testing at $140 \mathrm{slpm}$. These larger adsorber modules incorporated advances in the Microlith ${ }^{\circledR}$ technology and improved flow distribution through the to improve sorbent density and bed utilization which should translate into greater process efficiencies such as longer sorption half cycle time and higher volumetric sorption capacity.

\section{Conclusions}

Both the IBD and Microlith ${ }^{\circledR}$ process technologies have proven to be viable candidates for functional trade spaces of a core atmosphere revitalization process design. These process technologies have demonstrated improvement in performance relative to the ISS CDRA in regards to power consumption. Continued functional evaluation of components possessing higher functional removal capacity of at least $4 \mathrm{~kg} \mathrm{CO}_{2} /$ day as well as operating these components in a fully integrated configuration is necessary to further advance technical maturity and demonstrate reliability and universal applicability.

\section{References}

${ }^{1}$ Perry, J. L., Carter, R. N., and Roychoudhury, S., "Demonstration of an Ultra-Short Channel Metal Monolith Catalytic Reactor for Trace Contaminant Control Applications," 1999-01-2112, SAE, $29^{\text {th }}$ International Conference on Environmental Systems, Denver, Colorado, 1999.

${ }^{2}$ Perry, J. L., Frederick, K. R., Carter, R. N., Tatara, J. D., "Performance Demonstration of a Metal Monolith Catalytic Converter for Trace Contaminant Control," TM-1999-209262, NASA, 1999.

${ }^{3}$ Perry, J. L., Tomes, K. M., Roychoudhury, S., and Tatara, J. D., "Performance Characterization of a Prototype Ultra-Short Channel Monolith Catalytic Reactor for Air Quality Control Applications," 2005-01-2868, SAE, 35 ${ }^{\text {th }}$ International Conference on Environmental Systems, Rome, Italy, 2005.

${ }^{4}$ Perry, J. L., Tomes, K. M., and Tatara, J. D., "Thermal Catalytic Oxidation of Airborne Contaminants by a Reactor Using Ultra-Short Channel Length, Monolithic Catalyst Substrates," TM-2005-214061, NASA 2005.

${ }^{5}$ Roychoudhury, S., and Pfefferle, W. C., "Catalytic Reactor for Promoting a Chemical Reaction on a Fluid Passing Therethrough,” U.S. Patent No. 6328936, December 11, 2001.

${ }^{6}$ Roychoudhury, S., Walsh, D., and Perry, J., "Microlith-based Sorber for Removal of Environmental Contaminants," 200401-2442, SAE, 34 ${ }^{\text {th }}$ International Conference on Environmental Systems, Orlando, Florida, 2004.

${ }^{7}$ Roychoudhury, S., Walsh, D., and Perry, J., "Resistively-Heated Microlith-Based Adsorber for Carbon Dioxide and Trace Contaminant Removal," 2005-01-2866, SAE, $35^{\text {th }}$ International Conference on Environmental Systems, Rome, Italy, 2005.

${ }^{8}$ Roychoudhury, S., Perry, J., and Walsh, D., "Regenerable Adsorption System" U.S. Patent No. 7141092, November 28, 2006.

${ }^{9}$ Perry, J. L., Bagdigian, R. M., and Carrasquillo, R. L., "Trade Spaces in Crewed Atmosphere Revitalization System Development," AIAA 2010-6061, AIAA, 40 ${ }^{\text {th }}$ International Conference on Environmental Systems, Barcelona, Spain, 2010.

${ }^{10}$ Howard, D. F., Perry, J. L., Knox, J. C., and Junaedi, C., "Engineered Structured Sorbents for the Adsorption of Carbon Dioxide and Water Vapor from Manned Spacecraft Atmospheres: Applications and Testing 2008/2009," 2009-01-2444, SAE, $39^{\text {th }}$ International Conference on Environmental Systems, Savannah, Georgia, 2009.

${ }^{11}$ Nalette, T., Papale, W., and Smith, F., "Development Status of the Carbon Dioxide and Moisture Removal Amine Swingbed (CAMRAS), 2007-01-3157, SAE, 37 International Conference on Environmental Systems, Norfolk, 2007.

${ }^{12}$ Knox, J. C., Howard, D. F., and Perry, J. L., "Engineered Structured Sorbents for the Adsorption of Carbon Dioxide and Water Vapor from Manned Spacecraft Atmospheres: Applications and Modeling 2007/2008”, 2008-01-2094, SAE, 38 ${ }^{\text {th }}$ International Conference on Environmental Systems, San Francisco, 2008.

${ }^{13}$ Ametek Technical and Industrial Products, http://www.ametek.com [cited 24 March 2011].

14“Constellation Program Human-Systems Integration Requirements”, CxP 70024, Baseline Edition, Appendix E, 2006 